JOURNAL OF

HORTICULTURAL

SCIENCES
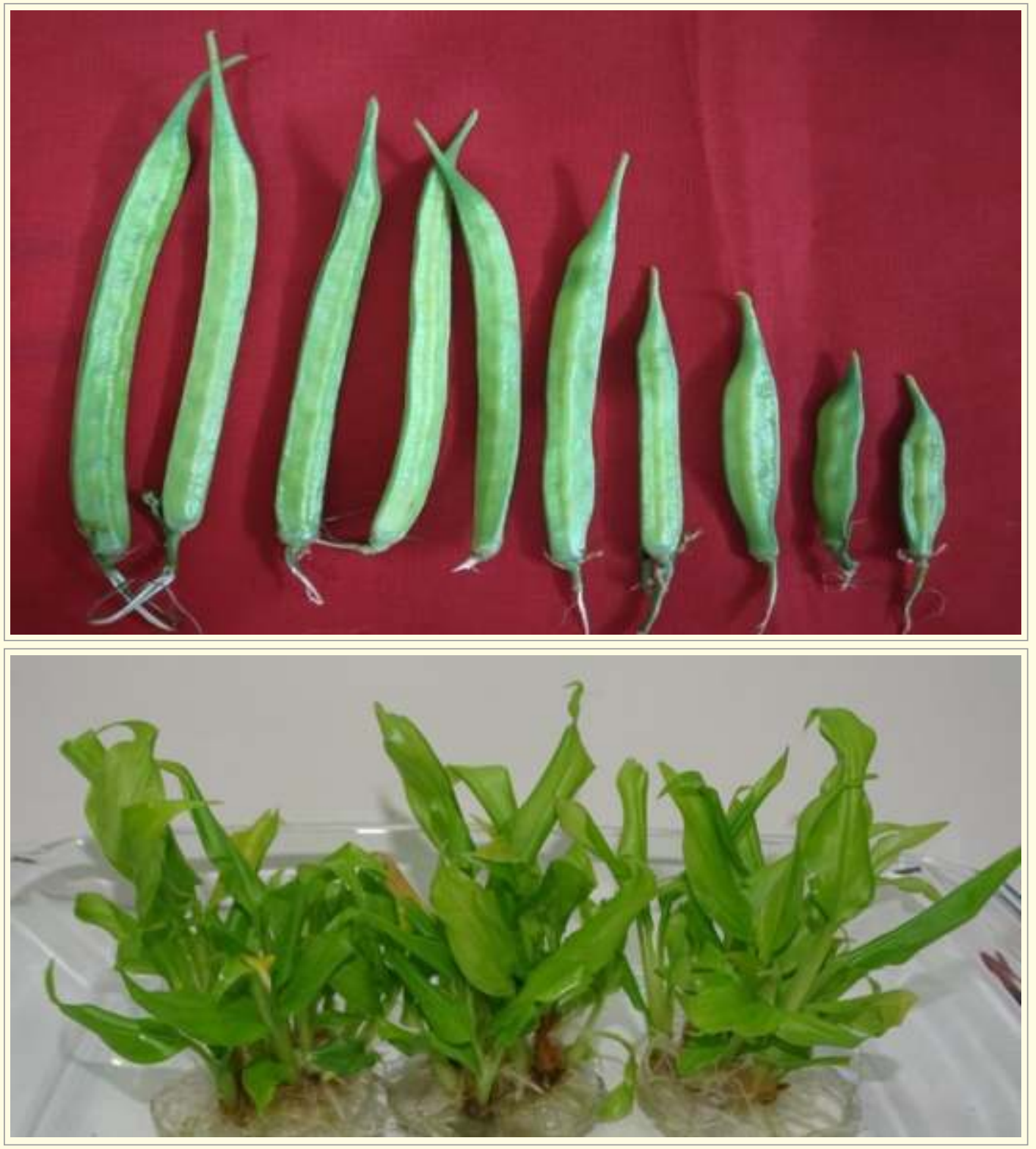

Society for Promotion of Horticulture

ICAR - Indian Institute of Horticultural Research, Bengaluru - 560089 


\section{JOURNAL OF HORTICULTURAL SCIENCES}

\section{ONTENTS}

\section{In this Issue}

\section{Review}

Moringa (Moringa oleifera L.): An underutilized and traditionally valued

tree holding remarkable potential

Jattan M., Kumari N., Raj Kumar, Kumar A., Rani B., Phogat D.S.,

Kumar, S. and Kumar, P.

\section{Original Research in Papers}

Characterization and evaluation of mountain sweet thorn

(Flacourtia montana J. Grah) collections

Tripathi P.C., Ganeshan S., Radhika V. and Shetti D.L.

Optimization of methodology for the extraction of polyphenolic compounds

with antioxidant potential and á-glucosidase inhibitory activity from jamun

(Syzygium cumini L.) seeds

Arivalagan M., Priyanka D.R. and Rekha A.

Genetic variability studies in amaranthus (Amaranthus spp.)

Agadi A.H., Kolakar S., Lakshmana D., Nadukeri S. and Hanumanthappa M.

Morpho-physiological parameters associated with chlorosis resistance to

iron deficiency and their effect on yield and related attributes in potato

(Solanum tuberosum L.)

Challam C., Dutt S., Sharma J., Raveendran M. and Sudhakar D.

Responses of different Okra (Abelmoschus esculentus) cultivars to water

deficit conditions

Ayub Q., Khan S.M., Hussain I., Naveed K., Ali S., Mehmood A., Khan M.J., Haq N.U., Shehzad Q.

Induced variability for yield and its attributing traits in cluster bean

[Cyamopsis tetragonoloba (L. ) Taub] through gamma irradiation

Lavanya H.N., Mishra S., Sood M., Aghora T.S., Anjanappa M., Rao V.K. and Reddy A.B.

In vitro multiplication protocol for Curcuma mangga : Studies on carbon,

Waman A.A., Bohra P., Karthika Devi R. and Pixy J. 
Effect of fungicide and essential oils amended wax coating on quality and shelf life of sweet orange (Citrus sinensis Osbeck)

Bhandari M., Bhandari N. and Dhital M.

Post-harvest quality and quantification of betalains, phenolic compounds and antioxidant activity in fruits of three cultivars of prickly pear

(Opuntia ficus-indica L. Mill)

Gonzalez F.P.H., Saucedo V.C., Guerra R.D., Suarez E.J., Soto H.R.M. Lopez J.A.,

Garcia C.E. and Hernandez R.G.

Soil microbial community dynamics as influenced by integrated nutrient management practices in sweet basil (Ocimum basilicum L.) cultivation Baraa AL-Mansour and D. Kalaivanan

Effect of spectral manipulation and seasonal variations on cut foliage production and quality of Philodendron (Philodendron 'Xanadu')

Sujatha A. Nair, Laxman R.H. and Sangama

\section{Short Communications}

Studies on mutagenic sensitivity of seeds of pummelo (Citrus maxima Merr.)

Sankaran M., Kalaivanan D. and Sunil Gowda D.C.

Isolation and characterization of microsatellite markers from

Garcinia indica and cross species amplification

Ravishankar K.V., Vasudeva R., Hemanth B., Nischita P., Sthapit B.R.,

Parthasarathy V.A. and Rao V.R. 


\title{
Studies on mutagenic sensitivity of seeds of pummelo (Citrus maxima Merr.)
}

\author{
Sankaran M. ${ }^{* 1}$, Kalaivanan D. ${ }^{2}$ and Sunil Gowda D.C. ${ }^{1}$ \\ ${ }^{1}$ Division of Fruit Crops, ${ }^{2}$ Division of Natural Resources ICAR-Indian Institute of Horticultural Research \\ Hesaraghatta Lake Post, Bengaluru - 560089 \\ *Corresponding author e-mail : kmsankaran@gmail.com
}

\begin{abstract}
Mutation breeding is a key method of generating large number of heritable variations. Effective dose $\left(\mathrm{LD}^{50}\right)$ needs to be standardized for inducing sufficient variation in a crop. In the present study, seeds were irradiated with different doses of Gamma rays and found that 66.94 Gy could suppress germination close to 50 per cent $\left(\mathrm{LD}^{50}\right)$ in pummelo. This 60 Gy gamma dose can effectively be used for raising the mutant populations to identify a desirable mutation in pummelo.
\end{abstract}

Keywords : Gamma Irradiation, Germination, Gray (Gy), LD ${ }^{50}$, Mutation and Pummelo

Induced mutation plays a significant role in the crop improvement of horticultural crops. It is an important tool for induction of variation in quantitative and qualitative characters. It can be a supplement to conventional breeding methods when it is desired to improve one or two characters in a well-adapted variety. Induced mutation improving crops cultivars, enhancing biodiversity and Gamma irradiations are safe for human and environment and can be used widely to develop new varieties in fruit crops. In the recent past, mutation using gamma rays is regularly attempted in the banana breeding program (Smith et al., 2006 and Mishra et al., 2007). Among the different strategies to enhance crop improvement programs, induced mutagenesis has contributed immensely by creating mutant varieties with improved and desirable genetic changes in agronomically important traits in crops. Much progress has been made in generating superior genotype with favourable attributes through induced mutations in fruit crops. Pummelo is the largest citrus fruit and known in the western world mainly as the principal ancestor of the grapefruit. Pummelo fruit, like all fruits of the citrus family has several health benefits because of its super - rich Vitamin $C$ and Vitamin B content. It also contains Vitamin A, Vitamin B1, B2 and C, bioflavonoid, healthy fats, protein, fibre, antioxidants and enzymes. It bears medium sized fruits $(1-1.5 \mathrm{~kg})$ with good TSS (8-10 $\left.{ }^{0} \mathrm{~B}\right)$ value. The pulp texture of pummelo fruit is fleshy and pulp colour is pink. Excessive bitter taste in citrus juice is a major problem in citrus industry worldwide because it reduces the quality and commercial value of the product (Mongkolkul et al., 2006). The bitterness in citrus fruit is affected by limonin and naringin, which are generally recognized as the major two bitter compounds. Limonin is the bitter limonoid found in major citrus cultivars such as grapefruit, the Navel orange, and the Shamouti orange (Guadagni et al., 1973). Naringin is not transported after being synthesized in the fruit or leaves. However, till date, there is no information about availability of sweet pummelo varieties or bitter free pummelo varieties across the globe. Hence, the present investigation is aimed to determine the optimal dosage of gamma irradiation (LD50) for mutation induction in seeds of pummelo genotype "Kallar Selection" (Deep pink pulp with high bitterness) for developing a mutant with desirable horticultural traits.

The present investigation was carried out at ICARIndian Institute Horticultural Research, Bengaluru560089. The seeds of Kallar Selection (Accession-6) pummelo were irradiated with different doses of gamma rays. The fresh and physically pure quality seeds of pummelo fruit were used for the irradiation purpose. In first step of experiment, a preliminary study was conducted to know the sensitivity of pummelo dry seeds to gamma radiation in which, pummelo seeds irradiated with gamma rays at the doses of 100 Gy, 200 Gy, 300 Gy, 400 Gy and 500 Gy. In second step of the experiment, based on preliminary results the pummelo fresh seeds were 
irradiated with gamma doses of 25Gy, 50Gy, 60Gy, 75Gy and 100Gy to determine the exact LD50. The irradiated seeds along with non-irradiated seeds (control) were sown in protrays filled with cocopeat and each protray was marked with given gamma dose. Thereafter, water was sprinkled over the protray to provide enough moisture for seed germination and it was kept in controlled condition. Different parameters (seed germination per cent, number of seed germinated and number of seed deformities during germination) related to determining LD50 was recorded in 60 days after sowing. The data were subjected to Chi-Square analysis and ChiSquare table was used for the calculation error degrees of freedom.

For any induced mutagenesis programme, it is necessary to fix the LD50 value based on which larger population can be raised to isolate the desirable mutant progeny/progenies. The LD50 value varies according to crop species, varieties, seeds or other planting materials, nature of treatment, method of raising, climate, cultural practices and other parameters (Singh, 1994). In Citrus, several attempts to induce variability with some traits of seedless, thorn less, color changed fruits and juices (Maluszynski et al., 2000). The radio-sensitivity (LD50) of acute citrus exposure ranges from 40 to 100 Gy (Sanada and Amano, 1998; Sparrow et al.,
1968), depending on the species and variety. The bud wood of pummelo Nambangan was irradiated with the dosage of 20, 40, and 60 Gy. The buds then grafted to Japanish Citron rootstocks. After three years of selection based on performance and fruit evaluation on MV2 generation, a mutant plant derived from 20 Gy irradiation treatments were obtained with improved character on the number of seeds. Pummelo Nambangan has more than 40 seeds/ fruit and the mutant has less than 10 seeds/fruit on average and it shows higher volume of juice compared to that in pummelo Nambangan. However, the fruit appearance between mutant plant and parent in term of the fruit shape had no difference, showing a combination of spheroid and pyriform shape. The difference between them was shown prominently when the fruit was cut, indicating the less seed contained and more intense red color of flesh of the mutant fruit compared to that of parent (Mariana et al., 2018.) In the initial study, pummelo seeds were treated with 100, 200, 300, 400 and 500 Gy). The effect of different doses of gamma rays ranging from 0 to 100 Gy on seed germination are shown in Table 1 and shown in Fig.1. The percentage of seed germination ranged from 18.31 per cent to 95.07percent with different doses of gamma rays in pummelo (Acc-06) as compared to 97.96 per cent in control.

Table 1: Effect of gamma irradiation in pummelo seed germination

\begin{tabular}{|l|c|c|c|c|c|}
\hline Treatment & $\begin{array}{c}\text { No of } \\
\text { seeds sown }\end{array}$ & $\begin{array}{c}\text { No of seeds } \\
\text { germinated }\end{array}$ & $\begin{array}{c}\text { No of under } \\
\text { developed } \\
\text { seedlings }\end{array}$ & $\begin{array}{c}\text { Days to } \\
\text { germination }\end{array}$ & $\begin{array}{c}\text { Germination } \\
\text { percentage }\end{array}$ \\
\hline Control & 98 & 96 & 0 & 10 & 97.96 \\
\hline Dosage 25 Gy & 98 & 93 & 0 & 11 & 94.90 \\
\hline Dosage 50 Gy & 98 & 88 & 0 & 11 & 89.90 \\
\hline Dosage 60 Gy & 98 & 46 & 21 & 14 & 46.94 \\
\hline Dosage 75 Gy & 98 & 24 & 16 & 20 & 24.49 \\
\hline Dosage 100 Gy & 98 & 18 & 14 & 20 & 18.37 \\
\hline
\end{tabular}

Gradual reduction/decrease in pummelo seed germination was observed with increase in gamma irradiation dose. The inhibitory effect on seed germination was directly proportional to the dose of gamma radiation. Similar results were reported by Dhatt et al. (2000) and Latado et al. (2001) with gamma radiation in citrus. Decrease in percent seed germination by gamma irradiation might be due to its effect on genetical and cytological processes coupled with the changes induced in metabolic processes. The decrease in seed germination was mainly due to the interference of mutagens with metabolic activities of the seeds (Sjodin, 1962). Sinha and Godward (1972) opined that the reduction in percentage of seed germination was due to the disturbances caused at the physiological level coupled 
with chromosomal damage. Disturbance in the formation of enzymes involved in the germination process may be one of the physiological effects caused by mutagenic treatments (Kulkarni,2011). Gamma radiation is well known for their action causing point mutations, enzyme inhibitions and chromosomal aberrations. The observed reduction in seed germination in pummelo as a result of gamma radiation might be due to point mutations or the injuries caused to the genetic material. This may eventually lead to decrease the rate of respiration and energy production, which finally caused decrease in seed germination. Days taken to germination and number of seeds with deformity were increased with increasing dose of gamma radiation. Based on probit analysis, 66.94Gy dose was found to be effective as
LD50 for irradiation of pummelo seeds (Table 2) to induce sufficient variation. This finding may assist as reference dose for large scale gamma irradiation of pummelo genotypes to induce genetic variation. However, considering the practical difficulty, its better fix $60 \mathrm{~Gy}$ as LD50 to induce sufficient mutation to select the desirable one. This result was in line with other studies on the effect of gamma rays in citrus. On lemon, Gulsen et al. (2007) obtained most seedless fruit from 50 Gy treatment while Spiegel-Roy et al. (2007) successfully obtained seedless fruit with 13.3 Gy. On mandarin, Kafa et al. (2015) obtained most mutant plants with seedless fruit with 30 Gy while Montanola et al. (2015) obtained seedless fruit with 40-50 Gy.

Table 2: Lethal dose calculation

\begin{tabular}{|c|c|c|c|l|l|}
\hline Pummelo & $\mathbf{n}^{\mathbf{a}}$ & $\begin{array}{c}\text { LD50 LCL-UCL } \\
\mathbf{( 9 5 \%} \text { confidence limit) }\end{array}$ & $\begin{array}{c}\text { LD90 LCL-UCL } \\
\text { (95\% confidence limit) }\end{array}$ & $\chi^{\mathbf{2}}$ & df \\
\hline $\begin{array}{c}\text { Gamma } \\
\text { irradiation }\end{array}$ & 98 & $\begin{array}{c}66.94 \\
(60.06-74.61)\end{array}$ & $\begin{array}{c}164.27 \\
(127.03-212.42)\end{array}$ & 9.4 & 4 \\
\hline
\end{tabular}

LD50 = lethal dose that kill $50 \%$ of the population; $\mathrm{n}^{\mathrm{a}}=$ population number; $\mathrm{LCL}=$ lower confidence limit; $\mathrm{UCL}=$ upper confidence limit

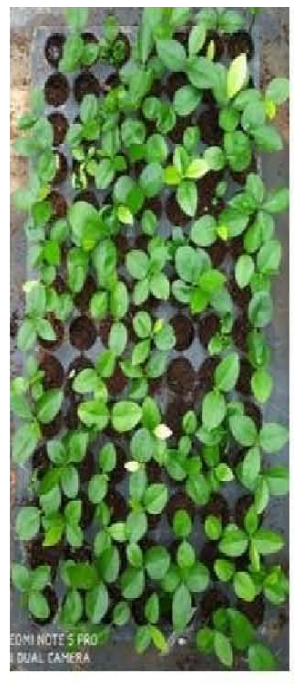

CONTROL

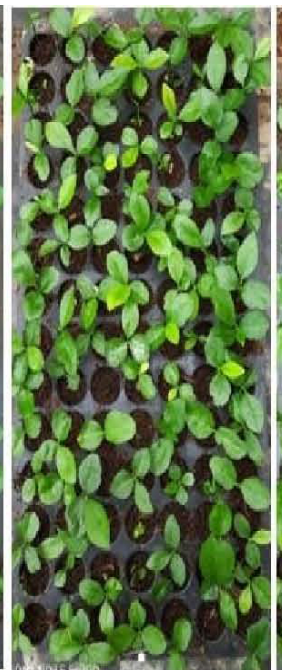

Dosage 25 Gy

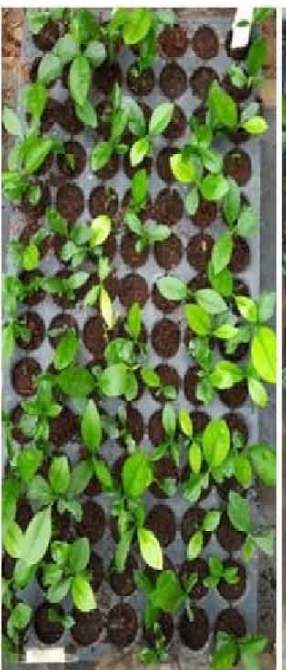

Dosage 50Gy

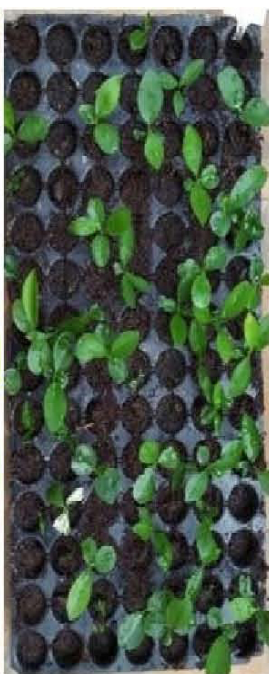

Dosage $60 \mathrm{~Gy}$

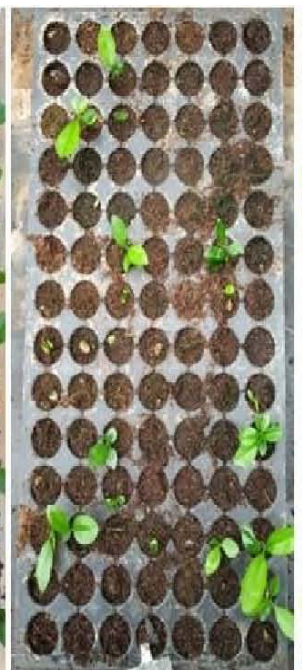

Dosage $75 \mathrm{~Gy}$

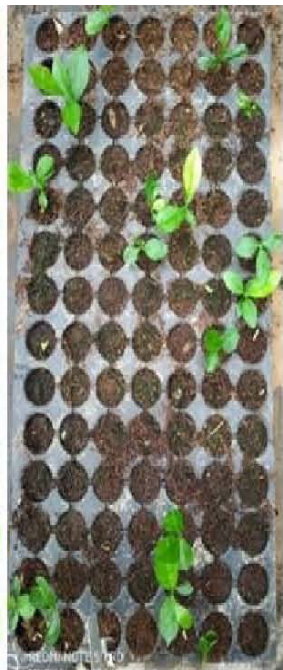

Dosage 100Gy

Fig.1: Mutagenic sensitivity of pummelo seedlings to different doses of gamma radiation

\section{ACKNOWLEDGEMENT}

Authors are thankful to the Indian Council of Agricultural Research, Ministry of Agriculture and Farmer's Welfare, GOI, for funding the project. 


\section{REFERENCE}

Dhatt, A S., Rattanpal, H. S., Khokhar, R. and Singh, S. N. 2000. Standardising LD50 dose of gamma rays and EMS in kinnow seeds. Journal of Research Punjab Agricultural University, 37 (3-4): 194-7.

Guadagni, D.G., Maier, V.P and Turnbaugh, J.G, 1973. Effects of some citrus constituents on taste thresholds for limonin and naringin bitterness. J. Sci. Food Agric., 24: 1199-1205.

Gulsen, O., Uzun, A., Pala, H., Canihos, E. and Kafa, G. 2007. Development of seedless and mal secco tolerant mutant lemons through bud wood irradiation. Scientia Horticulturae, 112: 184190.

Kafa, G., Seday, U., Uysa,1 O. and Polatoz, S. 2015. Effect of budwood irradiation on seed number of 'Clementine', 'Nova' and 'Robinson' mandarin mutants. Proc. XII Intl. Citrus Congress. Acta Horticulturae No. 1065, International Society for Horticultural Science, Leuven, Belgium.

Kulkarni, G. B. 2011. Effect of mutagen on pollen fertility and other parameters in horse gram (Macrotylomauni florum (Lam.) Verdc). Bio. Sci. Discovery, 2 (1): 146-150.

Mishra, P. J., Ganapathi, T. R., Suprasanna, P., Bapat, V. A. 2007. Effect of Single and recurrent gamma irradiation on in vitro shoot cultures of banana. Int. J. Fruit Sci.,7:45-57.

Latado, R. R., TulmannNeto, A., Ando A Iemma, A., F, Pompeu Junior, J., Figueiredo, J. O., Pio, R. M., Machado, M. A., Namekata, T., Ceravolo, L. and Rossi, A. C. 2001. Sweet orange 'Pera' mutants with low number of seeds obtained through mutation induction. Revista Brasileira de Fruticultura, 23 (2):339-44.

Maluszynski, M., Nichterlein, K., Vanzanten, L. and Ahloowalia, B. S. 2000. Officially released mutant varieties - the FAO/IAEA database. Mutation Breeding Review, 12: 1-84.

Mariana, B., Arisah, H., Yenni and Selvawajayanti. M. 2018. Seedless fruit pummelo induced by Gamma Ray irradiation: Fruit morphological characters and stability evaluation. Biodiversitas. 19(2): 706-711.
Mongkolkul, P., Rodart, P., Pipatthitikorn, T., Meksut, L. and Sanguandeekul, R. 2006 Debittering of Tangerine (Citrus reticulata Blanco.) Juice by B-Cyclodextrin polymer. J Incl Phenom Macrocycl Chem., 56:167- 170.

Montanola, M. J., Galaz, A., Gambardella, M. and Mártiz, J. 2015. New low seeded mandarin (Citrus reticulata) and lemon (C. limon) selections obtained by Gamma irradiation. Proc. XII Intl. Citrus Congress. Acta Horticulturae No. 1065, International Society for Horticultural Science, Leuven, Belgium.

Sanada, T. and Amano, E. 1998. Induced mutation in fruit trees. In Jain, SM., Brar, D. S. and Ahloowalia, B. S. Soma clonal variation and induced mutations in crop improvement. Kluwer Academic Publishers. England. p. 401419.

Singh, B.D. 1994. Mutations in crop improvement In Plant Breeding Kalyani Publ., Ludhiana p 434450

Sinha, S. S and Godward, N. 1972. Radiation studies in Lens culanaris. Induction of mutations and type of mutants. J. Cytol. Genet, 8: 131- 136.

Sjodin, J. 1962. Some observations in X1 and X2 of Vicia faba (L.) after treatment with different mutagens. Hereditas, 48: 565-586.

Smith, M. K., Hamill, S. D., Langdon, P. W., Giles, J. E., Doogan, V. J. and Pegg, K. G. 2006. Towards the development of a Cavendish banana resistant to race 4 of Fusarium wilt: gamma irradiation of micro propagated Dwarf Parfitt (Musa spp., AAA group, Cavendish subgroup). Aus. J. Exp. Agric., 46(1):107-113.

Sparrow, A. K., Rogers, A. F. and Schwenmer, S. S. 1968. Radio sensitivity studies which woody plants. I. Acute gamma irradiation survival data for 28 species and predictions for 190 species. Radiation Botany, 8:149-186.

Spiegel-Roy, P., Vardi, A., Yaniv, Y., Fanberstein, L., Elhanati, A. and Carmi, N. 2007. 'Ayelet' and 'Galya': New seedless lemon cultivars. Hort science, 42(7): 1723-1724.

\section{(Received on 28.10.2020, Revised on 03.04.2021, Accepted on 15.04.2021)}

